\title{
La llamada valoración negativa de la prueba en la doctrina y la jurisprudencia
}

\section{The So-Called Refusal to Assess Evidence in the Scholarship and Case Law}

\author{
Carlos CORREA RobleS*
}

\begin{abstract}
Resumen
El trabajo analiza la llamada valoración negativa de la prueba en el proceso penal chileno. Para ello, se presenta la jurisprudencia más relevante de los tribunales superiores tanto a favor como en contra de dicha posibilidad, exponiendo además la postura de la doctrina nacional. Como conclusión, se ofrece al lector una posición favorable a dicha valoración negativa, al entenderla como un mecanismo destinado a resguardar la efectiva protección las garantías fundamentales en la obtención de prueba, más allá de la regla de exclusión de prueba.
\end{abstract}

Palabras claves: proceso penal; derecho probatorio; prueba ilícita; valoración de la prueba.

\begin{abstract}
This paper analyzes the so-called refusal to assess evidence in the Chilean criminal process. For this purpose, the most relevant case law of the higher courts in favor and against this possibility is presented, while also explaining the doctrine's stance in this regard. In conclusion, the reader is provided with a position in favor of such refusal to assess evidence, understanding it as a mechanism to safeguard the effective protection of fundamental guarantees in obtaining evidence, beyond the exclusionary rule of evidence.
\end{abstract}

Keywords: criminal process; probatory law; illicit evidence; evidence valoration.

\section{INTRODUGGIÓN}

Recurrentemente, los problemas que suelen aquejar a los teóricos del derecho suelen tener escasa o nula aplicación práctica. La sofisticación que exige el adecuado tratamiento

\footnotetext{
${ }^{*}$ Universidad Adolfo Ibáñez, Chile (c.correa@uai.cl). Este artículo es parte de una investigación financiada mediante un proyecto Fondecyt Iniciación ( $\mathrm{N}^{\circ} 11190036$ : "La prueba ilícita en el proceso penal: más allá de la regla de exclusión", 2019-2022) cuyo apoyo agradezco en esta nota. Agradezco especialmente a Catalina Correa, por su colaboración en la recopilación de material para la confección del presente artículo, a la profesora Agustina Alvarado y a los árbitros anónimos por sus valiosos comentarios y sugerencias. Artículo recibido el 8 de abril de 2020 y aceptado para su publicación el 15 de enero de 2021.
} 
de las instituciones jurídicas, no busca restringir la discusión jurídica a las hipótesis relevantes para la opinión pública; de ser así, el razonamiento jurídico estaría supeditando su autonomía a criterios externos de discutible legitimidad.

Sin embargo, en otros momentos, la relevancia de ciertos problemas tratados por la doctrina alcanza un interés práctico considerable. En estas ocasiones, la abundante jurisprudencia que suele acompañar dichas discusiones, suele reflejar las distintas voces encontradas que dicho tema suscita en la literatura. El tratamiento de la ilicitud probatoria en el proceso penal chileno, y en concreto, del rol de los tribunales de juicio oral en dicha discusión, constituye un buen ejemplo de ello.

$\mathrm{Al}$ respecto, recordará el lector el conocido caso conocido como "armas de San Antonio", acaecido hace algún tiempo atrás. Los hechos del caso, ampliamente difundidos por la prensa de la época, se originaron a partir de un control de identidad efectuado a los ocupantes de un vehículo que transitaba por la comuna de El Tabo con la totalidad de los vidrios polarizados. Al momento de controlar a sus ocupantes, y posteriormente registrar el vehículo, el personal policial que efectuó la diligencia encontró al interior del vehículo diversas armas de fuego, abundante munición, dinero en efectivo y otros elementos cuya tenencia se encuentra legalmente proscrita.

A este respecto, la discusión jurídica versó sobre la legalidad del registro al vehículo en el cual los imputados transportaban las armas, y consecuentemente, sobre la legalidad de la evidencia incautada.

Discutida la admisibilidad de dicha prueba ante una solicitud de exclusión probatoria, planteada por la defensa en la audiencia de preparación del juicio oral, la Corte de Apelaciones de Valparaíso finalmente ratificó la validez de su obtención, permitiendo -en consecuencia- que ésta fuera incluida en el auto de apertura y posteriormente ofrecida en el juicio oral.

Sin perjuicio de dicha resolución, el Tribunal Oral en lo Penal de San Antonio absolvió a los imputados. El fundamento por el cual se llegó a esta conclusión se encuentra sintetizado en el considerando noveno de la sentencia de fondo, en el cual el tribunal hace explícito su parecer de "darle una valoración negativa a la prueba rendida en juicio". Al respecto, sostuvo el Tribunal, que de los dichos prestados en estrado por el funcionario policial encargado del procedimiento "quedó en evidencia su intento de justificar un procedimiento fuera de los márgenes legales".

Para llegar a tal conclusión -sostiene el considerando undécimo de la sentencia- adujo el Tribunal "razones doctrinarias, de texto y sistemáticas". Como justificación a ello, prosiguen, resulta necesario reconocer la protección de derechos fundamentales establecida en la normativa chilena, la cual impone al tribunal -en su calidad de órgano jurisdiccionalun deber de no convertirse en cómplice de una vulneración de dichas garantías, como la que se habría ocasionado al momento de controlar la identidad y posteriormente efectuar la detención de los acusados.

La sentencia causó enorme preocupación por parte de las autoridades de gobierno. $\mathrm{Al}$ respecto, la entonces vocera de gobierno Cecilia Pérez señaló que: "Los chilenos están aburridos de que el Poder Judicial se siga sorprendiendo en declaraciones (SIC) y no haga lo 
que tiene que hacer, que es hacer justicia. ¿O acaso los chilenos olvidan el caso en San Antonio de un vehículo lleno de armamento, cuyo juez dejó en libertad porque las pruebas no eran suficientes?". ${ }^{1}$

Como era de esperar, la sentencia absolutoria fue impugnada de nulidad, recurso que fue conocido por la Corte de Apelaciones de Valparaíso. Al respecto, por medio de resolución dictada el día 6 de agosto de 2019, el tribunal de alzada acogió el recurso interpuesto por el Ministerio Público en contra de la sentencia definitiva previamente pronunciada por el Tribunal Oral en lo Penal de San Antonio, ordenando la realización de un nuevo juicio oral por parte de un tribunal no implicado. En lo sustancial, la Corte de Valparaíso rechazó que el tribunal de fondo pueda valorar negativamente la prueba cuestionada rendida, previamente admitida en el auto de apertura.

La sentencia de nulidad no fue óbice para que en el segundo juicio oral, los acusados fueran nuevamente absueltos, defendiendo el tribunal de fondo, una vez más, la posibilidad de valorar negativamente la prueba ilícita.

La disparidad de criterios entre el Tribunal de Juicio Oral y la Corte de Apelaciones de Valparaíso recién expuesta constituye un reflejo de la complejidad del tema y de las distintas posiciones que éste suscita en la literatura y la jurisprudencia.

Como se expondrá a lo largo de este artículo, lo resuelto por los jueces de fondo y que en su momento fue desestimado por la Corte de Apelaciones respectiva, se enmarca dentro de una controvertida línea jurisprudencial desarrollada desde hace más de una década por parte de los tribunales superiores, y que busca dar solución a problemas referidos al origen antijurídico de ciertos elementos de prueba, incorporados - sin perjuicio de ello- a la audiencia de juicio.

A continuación, se expondrá la posición de la doctrina chilena al respecto, para posteriormente analizar aquellas sentencias de tribunales superiores de justicia que se hayan pronunciado sobre la posibilidad de valorar negativamente la prueba de cargo ilícitamente obtenida. Por último, corresponde exponer las razones que permitan llegar a una conclusión sobre la validez de la tesis descrita.

\section{CONGEPTO Y ALGANGE DE LA LLAMADA VALORAGIÓN NEGATIVA DE LA PRUEBA}

Ante todo, resulta necesario precisar el contenido y alcance de lo que la jurisprudencia ha denominado valoración negativa de la prueba. ${ }^{2}$

$\mathrm{Al}$ respecto, cabe recalcar en primer término algo evidente: dicho concepto no encuentra consagración alguna en la legislación vigente, sino que corresponde, en principio (y al menos en cuanto a su denominación), a una creación jurisprudencial chilena. Por

\footnotetext{
${ }^{1}$ LA TERCERA (2019): https://www.latercera.com/nacional/noticia/vuelco-caso-armas-san-antonio-anulanjuicio-absolvio-imputados/771607/

${ }^{2}$ Como se ha sostenido, no resulta del todo claro qué quiere decir la Corte cuando ha utilizado la expresión "valoración negativa". Vid. ARISTEGUI (2020), p. 192.
} 
valoración negativa, ha entendido la jurisprudencia, la actividad del juez de fondo dirigida a no considerar como medios de prueba susceptibles de fundar convicción en el tribunal, aquellos rendidos en el juicio oral y cuyo origen se vincula a una infracción de garantías fundamentales del imputado, cometida por los órganos de persecución criminal. Dicha valoración negativa queda plasmada en la sentencia definitiva y debe necesariamente ser fundamentada, caso a caso.

En este sentido, cabe tener presente un hecho trascendente para la discusión: la valoración negativa de la prueba se distingue de la exclusión probatoria, tanto en sus efectos, como en lo referido a la oportunidad procesal en la cual ambas instituciones operan.

Así, de acuerdo a lo establecido en el artículo 276 inc. $3^{\circ}$ del Código Procesal Penal $(\mathrm{CPP})$, la exclusión de prueba en virtud de su origen ilícito constituye un mecanismo que opera en la audiencia de preparación del juicio oral, siendo su efecto -sabemos- el impedir que un elemento probatorio ilícitamente obtenido, invocado por el fiscal en su libelo acusatorio, llegue a conocimiento del Tribunal de Juicio Oral. En este sentido, al excluirse del auto de apertura la prueba contaminada de ilicitud, se impide cualquier contacto del Tribunal de Juicio Oral con ésta, evitando de este modo la contaminación de dicho tribunal.

Por el contrario, la valoración negativa de la prueba opera no en la etapa intermedia, sino derechamente en el juicio oral ${ }^{3}$ y sólo en el caso en que la prueba rendida y cuestionada haya sido previamente admitida por parte del juez de garantía o por la Corte de Apelaciones, respectivamente. De este modo, y a diferencia de lo que sucede con la exclusión de prueba, en los casos en que el juez decide valorar negativamente la prueba cuestionada, es el mismo tribunal de fondo (el cual previamente recibió y conoció el medio de prueba controvertido), el que procede en su sentencia definitiva a no valorarla, descartándola como medio idóneo para fundar convicción. El actuar del Tribunal de Juicio Oral en este último caso no se condice con una exclusión de prueba, sino que se refiere exclusivamente a la valoración de la misma.

Como se expondrá posteriormente, a pesar de la denominación sui generis adoptada por nuestros tribunales, la valoración negativa de la prueba se relaciona íntimamente con las llamadas "prohibiciones de valoración de la prueba", reconocidas ampliamente por la doctrina y la jurisprudencia en el derecho procesal penal alemán y cuya procedencia en el derecho chileno, adelantamos, resulta atingente como mecanismo residual de protección de garantías en el proceso penal.

\section{LA VALORAGIÓN NEGATIVA DE LA PRUEBA EN LA DOGTRINA}

La discusión sobre la valoración negativa de la prueba en la literatura chilena tiene su origen, como es de esperar, en los años posteriores a la entrada en vigencia de la reforma procesal penal.

\footnotetext{
${ }^{3}$ Sin perjuicio de ello, resulta posible extender dicha institución a aquellas decisiones adoptadas por los jueces de garantía, ya sea durante la etapa de investigación o en procedimientos especiales, y en las cuales deba resolver en base a elementos de prueba ilícitamente invocados. Al respecto, vid. CORREA (2018), pp. 155 y ss.
} 
En realidad, como veremos, inicialmente la discusión doctrinaria no versó específicamente sobre la creación jurisprudencial que aquí se analiza, sino que recayó en la posibilidad de reconocer algún tipo de sanción procesal respecto de aquella prueba erróneamente admitida en la audiencia de preparación. Si bien al respecto es posible encontrar posiciones que datan de los primeros años de la reforma, las posturas que buscan hacerse cargo del problema desde la jurisprudencia han surgido especialmente en los últimos años. A continuación, nos haremos cargo de ellas.

\subsection{La posición a favor de la valoración negativa de la prueba en la literatura}

En su monografía dedicada al tratamiento de la prueba ilícita, Hernández ${ }^{4}$ postuló la improcedencia de que el Tribunal de Juicio Oral valore en su sentencia aquellos elementos de prueba obtenidos mediante vulneración de garantías fundamentales, no excluidos en la audiencia preparatoria.

Tal conclusión se fundamenta, de acuerdo al autor, en el art. 276 CPP, disposición que desempeñaría un papel más allá del control probatorio, al consagrar una verdadera prohibición general de valoración de prueba obtenida con infracción de garantías fundamentales, aplicable, consecuentemente, al juicio oral. ${ }^{5}$ De este modo, el Tribunal de Juicio Oral - sin perjuicio de no poder excluir prueba- no debiese mantenerse al margen de efectuar un análisis de la licitud del medio de prueba que ante él se ofrece, siéndole posible no valorar la prueba ilícitamente obtenida. ${ }^{6}$

En un sentido similar, nos decantamos en un artículo recientemente publicado ${ }^{7}$ a favor de reconocer la posibilidad de parte del Tribunal de Juicio Oral de no valorar la prueba de cargo ilícitamente obtenida, situación que permite reconocer en nuestro ordenamiento jurídico, la existencia de prohibiciones de valoración de prueba, institución propia del derecho alemán. Dicha posibilidad residual, se condice con el deber que asiste a todo tribunal que ejerza competencia en materia penal, de no valorar aquella prueba obtenida con infracción de garantías. La omisión de dicho deber daría lugar a una nueva infracción de garantías en perjuicio del imputado, esta vez al fundamentar una decisión jurisdiccional en base a prueba ilícita.

\subsection{La posición en contra de la valoración negativa de la prueba en la literatura}

En nuestro medio, una de las primeras voces en oponerse a la posibilidad de que el Tribunal de Juicio Oral efectúe un examen de licitud probatoria en sede de valoración, fue Julián López. ${ }^{8}$ En su reconocido manual, sostiene dicho autor que el Tribunal de Juicio Oral

\footnotetext{
${ }^{4}$ Hernández (2002), pp. 89 y ss. y Hernández (2008), p. 60. En un sentido similar, DonOso (2008), pp. 39 y ss.

5 Hernández (2002), p. 90.

${ }^{6}$ HERNÁNDEZ (2002), p. 90.

${ }^{7}$ CORrea (2018), pp. 162 y ss.

${ }^{8}$ Horvitz y LÓPEZ (2004), pp. 200 y ss. En este sentido, vid. EGHEVERRía (2010), pp. 72 y ss.
} 
debe valorar toda la prueba rendida en juicio en cuanto a su mérito para formar convicción, sin excepción.

Para llegar a dicha conclusión, sostiene el autor que la posibilidad de cuestionar la licitud de origen de la prueba ya rendida comprometería la estructura misma del sistema de ilicitud probatoria consagrado en el CPP, el cual le otorga dicha función de manera privativa al juez de garantía, en la audiencia preparatoria. ${ }^{9}$ Lo anterior, socavaría las funciones de dicho juez, al radicar en último término el examen de licitud probatoria en el Tribunal de Juicio Oral.

Adicionalmente, recurre el autor a un argumento de texto para sustentar su posición, al señalar que la ley no le ha entregado al tribunal dicha competencia, excediendo dicha posibilidad las funciones expresamente otorgadas por el ordenamiento. ${ }^{10}$ Finalmente, refiere el autor a los mecanismos de impugnación establecidos en el CPP y que permiten solucionar errores cometidos por el juez de garantía al decidir sobre la exclusión de prueba. En este sentido, sostiene López, el recurso de nulidad se erige como el mecanismo procesal que permitiría a la defensa impugnar dichos errores, en caso de que el tribunal de fondo hubiera valorado dicha prueba cuestionada en su sentencia condenatoria. ${ }^{11}$

En un artículo recientemente publicado, ${ }^{12}$ Jorge Cortés-Monroy ha planteado una interesante crítica a la noción y fundamento de la denominada "valoración negativa de la prueba."

$\mathrm{Al}$ respecto, sostiene dicho autor en primer término, que una vez la prueba ha sido admitida en la audiencia de preparación, el Tribunal de Juicio Oral se encontraría obligado - de conformidad al artículo 297 CPP- a valorar y considerar en su sentencia definitiva toda la prueba producida.

Argumenta dicho autor, que la discusión sobre exclusión probatoria planteada en la etapa intermedia compartiría los elementos de la cosa juzgada respecto de la valoración negativa de la prueba plasmada en la sentencia definitiva. De este modo, si un tribunal decide valorar negativamente la prueba, concluye, "se pronuncia en realidad sobre un asunto que ya ha sido resuelto por el juez de garantía." 13 Consecuentemente, un cuestionamiento de la licitud probatoria por parte del tribunal de fondo se encuentra vedado. ${ }^{14}$

En segundo término, afirma el autor, igualmente a partir de la cosa juzgada, y teniendo la valoración negativa de la prueba solo efectos una vez que el auto de apertura del juicio oral se encuentra firme, que dicho ejercicio vulneraría el contenido de una resolución inimpugnable e irrevocable, ${ }^{15}$ contraviniendo ello el ya referido límite.

En tercer lugar, recurre el autor a la historia del CPP para sostener que el legislador decidió limitar la impugnación del auto de apertura del juicio oral exclusivamente a la

\footnotetext{
${ }^{9}$ Horvitz y LÓPEz (2004), pp. 200 y ss.

${ }^{10}$ HORVITZ y LÓPEZ (2004), pp. 201 y s.

11 HORVITZ y LÓPEZ (2004), p. 203.

12 Cortés-Monroy (2018), pp. 661-692.

13 Cortés-Monroy (2018), pp. 684 y s.

14 Cortés-Monroy (2018), pp. 683 y s.

15 Cortés-Monroy (2018), pp. 685 y s.
} 
interposición del recurso de apelación por parte de la fiscalía, no pudiendo de este modo el tribunal -concluye- excluir prueba que ha sido admitida por el juez de garantía.

Como último argumento, defiende Cortés-Monroy (en un sentido similar a López), en base al régimen de legalidad que rige la actuación de los tribunales, que no encontrándose el Tribunal de Juicio Oral facultado para excluir prueba obtenida con infracción de derechos fundamentales, dicha posibilidad se encontraría vedada a su respecto, actuando -en caso contrario- fuera del ámbito de su competencia. ${ }^{16}$

En un trabajo igualmente reciente, Juan Pablo Aristegui se ha manifestado en contra de que los tribunales orales realicen una valoración negativa de la prueba en la sentencia definitiva. Para sustentar su posición, afirma el autor en primer lugar, que una vez consumada la valoración negativa de la prueba, el tribunal de juicio, sea de manera deliberada o no, "se verá en la necesidad de cubrir con sombras las auténticas razones de su decisión y racionalizar su justificación." Por ello, prosigue, dicha posibilidad afectaría la justificación de la decisión del tribunal sobre los hechos. ${ }^{17}$

De este modo, concluye, al no poder valorar el tribunal de fondo la prueba cuestionada, conduciría a justificar "inferencias probatorias en la misma línea señalada por la prueba (negativamente valorada), pero con un menor grado de corroboración." Dicho ejercicio, se aplicaría - prosigue- a aquellos elementos de juicio que no consiguen afirmar el grado de probabilidad suficiente para dar por probada la hipótesis. ${ }^{18}$

Lo anterior incidiría directamente - afirma a continuación- en el recurso de nulidad. $\mathrm{Al}$ no poder ser controlada por medio de este recurso la valoración de la prueba efectuada por el tribunal de fondo, la "hipervaloración" probatoria antes referida, no sería controlable por esta vía. Como consecuencia de lo anterior, la denuncia de infracción de garantías carecerá de la necesaria sustanciabilidad, impidiendo configurar el requisito de la trascendencia necesaria para hacer procedente la nulidad. ${ }^{19}$

\section{LA VALORAGIÓN NEGATIVA DE LA PRUEBA EN LA JURISPRUDENGIA DE LOS TRIBUNALES SUPERIORES}

La Corte Suprema, así como distintas Cortes de Apelaciones del país, han mantenido distintas posiciones en lo referido a la posibilidad de otorgar a la prueba una valoración negativa, pronunciándose en su mayoría a favor de dicha posibilidad. Analizaremos a continuación ambas posturas.

\footnotetext{
16 CORTÉs-Monroy (2018), pp. 687 y ss.

17 Aristegui (2020), p. 193.

18 Aristegui (2020), p. 193.

19 Aristegui (2020), p. 195.
} 


\subsection{Sentencias que han aceptado una valoración negativa de la prueba}

Una de las primeras oportunidades en las cuales la Corte Suprema se pronunció a favor de una valoración negativa de aquella prueba ilícitamente obtenida, corresponde a la sentencia Rol 3.570-06, pronunciada el 20 de septiembre de 2006, ${ }^{20}$ resolución que en sus considerandos 14 a 16 entrega diversos fundamentos en sustento de la referida posibilidad.

En cuanto a los hechos que dieron lugar a dicho pronunciamiento, tras efectuar un control de identidad de conformidad a lo dispuesto en el artículo 85 CPP, y luego de la comprobación de la identidad del imputado, registró la policía sin autorización y excediendo el ámbito de aplicación de dicho control, el automóvil del imputado. Desde el interior de éste, obtuvo la policía la droga que posteriormente sirvió de evidencia incriminatoria en contra del acusado. Dicha prueba, cabe destacar, no fue excluida en la audiencia de preparación al estimar el tribunal de garantía que su obtención se habría efectuado conforme a derecho.

Posteriormente, el Tribunal de Juicio Oral decidió absolver al acusado de los delitos imputados, al considerar - discrepando del juez de garantía- que la prueba de cargo fue obtenida sin contar la policía con la autorización necesaria para ello.

Al desestimar el recurso de nulidad interpuesto por el Ministerio Público en contra de dicha resolución, sostuvo el máximo tribunal que la posibilidad de restar valor probatorio en la sentencia definitiva a la prueba aportada y producida en el juicio oral en razón de su ilicitud de origen, valorándola negativamente, permite cumplir a cabalidad las exigencias de razonamiento propias de la sentencia definitiva. Al respecto, sostuvo el fallo, el "descarte" por ilicitud corresponde efectivamente a una valoración probatoria, razón por la cual, concluye:

[s]e procedió a restarle mérito o valor probatorio (a la prueba cuestionada), situación que (...) satisface las exigencias de fundamentación del fallo y no puede ser considerada como lo pretende el recurrente, un acto de exclusión de la misma, correspondiendo por el contrario y precisamente, a aquel proceso intelectual razonado y lógico, que (...) han hecho los sentenciadores.

Consistente con lo anterior, desestima finalmente la Corte en su resolución, que la facultad del Tribunal de Juicio Oral de valorar negativamente la prueba implique un desconocimiento de lo previamente resuelto por el juez de garantía en el auto de apertura (el cual, recordemos, rechazó excluir la prueba cuestionada por la defensa), desde que esta resolución:

[s] i bien fija los medios de prueba a rendir en la audiencia del juicio oral, su valoración en miras a la decisión de la controversia, es atribución privativa de los sentenciadores llamados por ley a resolverla, esto es, los Jueces del Tribunal del Juicio Oral respectivo.

${ }^{20}$ Ministerio Público con P.R.C.E. (2006). 
En los años siguientes, la Segunda Sala de la Corte Suprema se manifestó reiteradamente a favor de la posibilidad de valorar negativamente aquella prueba rendida en juicio, y cuya obtención se vincula a un acto atentatorio de garantías fundamentales, paradigmáticamente una detención ilegal. ${ }^{21}$ Sin embargo, dicha jurisprudencia, más allá de reconocer dicha posibilidad, no se explayó mayormente en los motivos para llegar a tal conclusión.

Casi una década después de la sentencia antes citada, en causa Rol No 23.683-2014, entregó la Corte Suprema nuevos fundamentos en defensa de la valoración negativa de la prueba por parte del Tribunal de Juicio Oral. ${ }^{22}$

En concreto, sostuvo el máximo tribunal en dicha oportunidad, que al haber sido declarada ilegal la detención del imputado, la ilicitud se vincula a todos los resultados generados por ella, lo que -sostiene- importa "extender la exclusión por valoración negativa de la prueba producida en la audiencia respectiva". Dicha conclusión, permite vincular la valoración negativa de la prueba a la totalidad de los elementos probatorios conectados a una actuación ilícita, reconociéndole por esta vía un efecto reflejo, propio de la ilicitud probatoria.

Asimismo, sostuvo la Corte en aquella oportunidad, que la valoración en la sentencia de los antecedentes probatorios vinculados a una ilicitud, revestidos de ilegalidad, importa:

la materialización de la infracción a las garantías constitucionales del imputado que aseguran su derecho a un debido proceso y a que la sentencia que se pronuncie por el tribunal sea el resultado de una investigación y un procedimiento racionales y justos, por cuanto dicha exigencia supone que cada autoridad actúe dentro de los límites de sus propias atribuciones, como lo señalan los artículos 6 y 7 de la Constitución Política de la República, lo que en este caso quedó de manifiesto que no ocurrió, infracción que solo puede subsanarse con la declaración de nulidad del fallo y del juicio que le precedió (...).

Posteriormente, mediante sentencia Rol 6783-2017, de 17 de abril de 2017, la Segunda Sala del máximo tribunal se manifestó nuevamente a favor de la posibilidad de efectuar una valoración negativa de la prueba de cargo, ${ }^{23}$ señalando (considerando $5^{\circ}$ ) que dicha teoría constituye: "una instancia más - adicional al control de detención y la audiencia de preparación de juicio oral- para discutir y probar la ilicitud de la prueba de cargo". sentido.

Lo anterior ha conformado, a juicio de la Corte, una jurisprudencia uniforme en tal

Si bien la mayoría de los pronunciamientos de tribunales superiores sobre el tema que nos convoca han sido emitidos por la Corte Suprema en conocimiento de la causal de nulidad contenida en el artículo 373 letra a) del CPP, en la sentencia pronunciada en causa Rol 3.103-

\footnotetext{
21 Vid. Corte Suprema caso Ministerio Público con E.V.O. (2015). En este mismo sentido, la prevención hecha por la Ministra Muñoz y el Ministro Valderrama, contenida en sentencia de la Corte Suprema Canales Espinoza contra Tribunal Oral en lo Penal de Iquique (2018). En el mismo sentido: Ministerio Público con R.H.A.G. (2019); Ministerio Público con R.A.C.P. (2016).

${ }^{22}$ Ministerio Público con S.E.A.R. (2014).

${ }^{23}$ Ministerio Público con D.V.C. (2017).
} 
2017, la Corte de Apelaciones de Santiago validó la posibilidad adoptada por parte del tribunal de fondo, en orden a valorar negativamente aquella prueba obtenida como consecuencia de una actuación ilegal, ${ }^{24}$ sosteniendo:

Que (...) se hace necesario destacar que todos los fundamentos de la sentencia apuntan a la ilicitud del procedimiento policial, en primer lugar, en relación al supuesto comprador de la droga, luego para descartar la hipótesis de flagrancia y finalmente para estimar que en la entrada y registro al domicilio de las acusadas, carabineros excedieron sus atribuciones, actuando en forma ilegalidad (sic). En este escenario, la sentencia atacada contiene los fundamentos que justifican la no valoración de la prueba, (...) y por tal motivo existiendo un razonamiento lógico para ello no es dable exigir a los sentenciadores que ponderaran aquello que han descartado por haberse obtenido con vulneración de garantías constitucionales.

En una sentencia dictada hace pocos años, la Corte de Apelaciones de Valparaíso en Ministerio Público con B.C.E. (2017) validó la posibilidad de que el Tribunal de Juicio Oral valore negativamente la prueba de cargo ilícitamente obtenida. Al respecto, reafirmó con ello la vigencia transversal de las garantías fundamentales en el proceso penal, al sostener que:

la convicción que se asienta en el artículo 340 del código de enjuiciamiento penal, debe ser lograda conforme a la prueba producida e incorporada en conformidad a la ley, con apego irrestricto a nuestro ordenamiento jurídico y respetuoso de las garantías reconocidas constitucionalmente, con prueba obtenida conforme a dicho respeto porque solo de esta manera se obtiene la certeza que las decisiones judiciales no se basen en medios ilícitos (...) sostener lo contrario implica obligar al juzgador a valorar y sentenciar en base a una prueba que, a sabiendas, se generó con infracción de garantías constitucionales lo que carece de razón y se aparta del sentido de justicia.

En segundo lugar, descartó el tribunal de alzada la pretendida imposibilidad de discutir nuevamente un asunto ya zanjado en la audiencia de preparación, recalcando que admisibilidad y valoración de prueba, obedecen a dos conceptos distinguibles entre sí:

el Tribunal Oral en lo Penal (...) debe pronunciarse respecto a la ineficacia de la prueba ilícita, aun cuando ello ya haya sido discutido ante el Juzgado de Garantía en la oportunidad establecida en el artículo 276 del Código Procesal Penal porque si bien en dicho tribunal se discutió respecto a la admisibilidad, es labor del Tribunal Oral en lo Penal discutir respecto a la ineficacia de prueba ilícita en cuanto un problema de valoración puesto que es ahí en donde se genera el valor probatorio de las mismas.

Por último, en un fallo recientemente pronunciado (causa Rol No 375-2019), la Corte de Apelaciones de Valparaíso se pronunció a favor de valorar negativamente aquellos elementos de prueba ilícitos erróneamente admitidos en la etapa intermedia, reconociendo la existencia de un verdadero imperativo dirigido a los jueces de fondo en ese sentido. ${ }^{25}$ Sostuvo en concreto, que ante:

${ }^{24}$ Ministerio Público con F.A.R. y otra (2017).

${ }^{25}$ Ministerio Público con M.J.B. y otros (2019). 
la constatación de que en el juicio se aportó una prueba ilícita, el Tribunal Oral en lo Penal debe valorarla negativamente, pudiendo examinarse los medios probatorios existentes, en virtud del principio de inmediación y de contradictoriedad; no siendo posible que los sentenciadores formen su convicción de condena sobre la base de una prueba que consideran obtenida ilegalmente. El artículo 276 del Código Procesal Penal impide que los jueces puedan valorar positivamente una prueba lograda con vulneración de las garantías constitucionales de los imputados.

De igual manera, la Corte de Apelaciones referida descartó en dicha oportunidad uno de los principales cuestionamientos opuestos por la doctrina a esta teoría, referido a la compatibilidad de la valoración negativa con lo previamente resuelto en la audiencia preparatoria. $\mathrm{Al}$ respecto, descartó la Corte un efecto de cosa juzgada, al primar ante todo la necesidad de impedir que una sentencia condenatoria se funde en una vulneración de garantías:

La circunstancia que ya haya existido previamente un pronunciamiento sobre el particular por parte del juez de garantía, no es óbice para decidir la valoración negativa de la prueba ilícita. Más aún, el Tribunal Oral en lo Penal debe prescindir de esta prueba, pues lo contrario llevaría a concluir que dicho tribunal debe fallar en la conciencia y conocimiento de la vulneración de garantías constitucionales y procesales de los imputados. En atención a este deber, es imposible que pueda concluirse que una sentencia absolutoria, en estas condiciones, vulnera la cosa juzgada a la que se refiere la letra g) del artículo 342 del Código Procesal Penal, ya que, por lo señalado, a este respecto dicha causal no puede configurarse.

\subsection{Sentencias que han rechazado la posibilidad de valorar negativamente la prueba}

En otras oportunidades, los tribunales superiores se han pronunciado en contra de la posibilidad de admitir que el tribunal de fondo efectúe una valoración negativa de aquella prueba obtenida con infracción de garantías, previamente admitida en el auto de apertura. Así, en causa Rol No 2.521-2008, sostuvo el máximo tribunal: ${ }^{26}$

Que (...) parece necesario enfatizar que el tribunal oral no puede excluir pruebas si ello no se hizo en sede de garantía, así como tampoco puede dejar de valorar la legalmente producida e incorporada en la audiencia de juicio oral, como parece sugerir la defensa, pues el legislador manda hacerse cargo de toda la prueba producida, sin perjuicio, claro está, que pueda desestimar alguna indicando las razones que tuvo en cuenta para ello.

Igualmente en contra de aceptar la posibilidad de valorar negativamente la prueba, atendida su admisión en la audiencia de preparación del juicio oral, la Corte de Apelaciones de La Serena afirmó en sentencia Rol $\mathcal{N}^{\circ}$ 319-2012 que:

${ }^{26}$ Ministerio Público con F.A.R.S. (2008). 
(...) no comparte la afirmación hecha por el abogado defensor, en cuanto a que respecto a dichas pruebas el tribunal oral y esta misma Corte o debería abstenerse de valorarlas o valorarlas negativamente, puesto que habiendo sido una prueba aceptada e incorporada al juicio, sin reproche alguno, corresponde su análisis y valoración como cualquier otra prueba agregada a los autos.

En otra decisión, la Corte de Apelaciones de Santiago en Ministerio Público con E.E.B (2017), ha entendido que el efecto que genera una valoración negativa de la prueba resulta asimilable a aquel propio de la exclusión probatoria generada como consecuencia de la aplicación del artículo 276 del CPP, siendo con ello, improcedente. En palabras de dicho tribunal:

esta Corte advierte que el tribunal a quo realizó aquello denominado por la jurisprudencia de nuestros tribunales como 'valoración negativa de la prueba', que en los hechos configura una forma de exclusión de prueba ilícita por parte del tribunal oral en lo penal, bajo pretexto de evitar su análisis por estimar que dicha prueba ha sido obtenida con vulneración de garantías constitucionales (...).

En segundo lugar, afirmó el tribunal capitalino en dicha oportunidad, que la valoración de la prueba a cargo del Tribunal de Juicio Oral no permite efectuar un examen sobre el origen de la prueba que ante dicho tribunal se rinde. Para ello entrega diversos argumentos los cuales, dada su relevancia para la discusión, serán reproducidos a continuación:

[La] valoración [de la prueba] constituye una actividad del juez con el objeto de determinar el grado de apoyo o refutación que un determinado conjunto de pruebas otorga a las hipótesis jurídicamente relevantes, sin incluir en dicho examen cuestiones que pudieren llevar a establecer que ciertas pruebas fuesen inoportunas. Lo relevante que debe ser valorado en relación a una prueba es su grado de corroboración o refutación de las proposiciones fácticas. Luego, cuando el tribunal valora negativamente una prueba que estima ilícita, no está en rigor valorando una característica intrínseca a la prueba producida, sino el medio a través del cual dicha prueba fue obtenida, lo que en la especie no corresponde, desde que con dicho procedimiento se está vulnerando lo que al efecto establecen los artículos 297 y 342 letra c) del código citado (...).

OGTAVO: Que la afirmación anterior no importa sostener que los jueces llamados a valorar la prueba tengan un supuesto deber de fallar conscientemente con fundamento en la vulneración de garantías constitucionales. Solo se trata de que, por diseño del sistema, el Tribunal de Juicio Oral en lo Penal es el único llamado a ponderar o valorar las probanzas rendidas en el juicio oral y ésta no es sólo una prerrogativa, sino también un deber ineludible.

Por último, en relación a la distribución de funciones a lo largo del proceso penal, rechazó la Corte en dicha oportunidad que el Tribunal de Juicio Oral pueda controlar la licitud de la prueba en cuanto a su origen, concluyendo que aquel órgano debe abstenerse de efectuar cualquier análisis al respecto: 
La eventual contravención de garantías fundamentales en la obtención de la prueba tiene en la ley diversos mecanismos de control, ya sea en la solicitud de exclusión que puede formularse ante el Juzgado de Garantía en la audiencia de preparación del juicio oral conforme lo estatuye el artículo 276, o bien por la Corte Suprema al conocer del recurso de nulidad en virtud de la mencionada causal de la letra a) del artículo 373, pero no tiene esta facultad del Tribunal de Juicio, el que, guste o no, debe limitarse a valorarla, en el sentido de otorgarle mérito en orden a tener o no por existente el hecho que con ella se pretende demostrar. Dicho de otro modo, para el Tribunal Oral debe ser indiferente la forma como la prueba haya sido recogida, no porque esta circunstancia sea efectivamente indiferente, sino porque la labor que le encomienda la ley no es ésta, sino una diversa, referida a la decisión acerca de la fuerza de persuasión que la prueba tenga.

Concluye el tribunal de alzada, calificando la valoración negativa como un "fraude de etiquetas", en tanto dicha actividad encubriría una exclusión de prueba.

Por último, parte importante de los argumentos expuestos por la doctrina para oponerse a la valoración negativa, fueron recogidos recientemente por la Corte de Apelaciones de Valparaíso en sentencia Rol No 1.337-2019, Ministerio Público con M.O.M. (2019), referida al ya mencionado caso "armas de San Antonio", al acoger el recurso de nulidad interpuesto por el Ministerio Público en contra de la (primera) sentencia absolutoria dictada por el Tribunal de Juicio Oral de San Antonio.

Para acoger dicho recurso, sostuvo la Sala en primer lugar, que habría operado la cosa juzgada respecto de la exclusión de prueba, no pudiendo pronunciarse el tribunal oral respecto de la ya dilucidada legalidad del control de detención, fuente de la ilicitud probatoria denunciada. ${ }^{27}$ Por lo anterior, concluye el tribunal de alzada, al momento de valorar negativamente parte de la prueba de cargo ofrecida por el ente acusador, el Tribunal de Juicio Oral habría desconocido lo previamente decidido "retrotrayendo su actuación a etapas pretéritas al juicio oral, sin que siquiera tal ilicitud haya emergido de la rendición misma de la prueba en el juicio oral."

Sostuvo finalmente la Corte que los sentenciadores, lejos de efectuar una valoración negativa de la prueba, habrían omitido una valoración de la misma, lo cual incumpliría los requisitos previstos en el artículo 297 CPP. Lo anterior configuraría una falta de fundamento en el razonamiento empleado por los sentenciadores al absolver a los acusados.

Descrita la posición de la doctrina y la jurisprudencia sobre el tema, corresponde ahora determinar la idoneidad de la tesis aquí analizada.

\footnotetext{
${ }^{27}$ En su prevención, el Ministro Sr. Droppelmann sostiene - disintiendo del voto de mayoría- que en la especie no resulta posible tener por acreditada la triple identidad de la cosa juzgada dado que la discusión sobre la ilicitud de la prueba promovida ante el juez de garantía resulta distinta de la apreciación de la prueba que los jueces del fondo deben efectuar. Asimismo, afirma que la exigencia de razonamiento probatorio esgrimida por el voto mayoritario en base a lo dispuesto en los artículos 297 y 342 letra c) CPP solo resulta aplicable en caso que se den por acreditados los hechos de la acusación; y no para el caso que estos no se tengan por establecidos, caso en el cual, prosigue, "se debe dar aplicación a lo dispuesto en el inciso segundo del artículo 297 que, rebajando las exigencias legales, solo obliga a dar las razones por las cuales se desestimó la prueba, sin exigir su valoración."
} 


\section{EL RECONOGIMIENTO DE LAS GARANTÍAS FUNDAMENTALES EN EL PROGESO PENAL GHILENO Y SUS MEGANISMOS DE RESGUARDO}

Como ha sostenido Roxin, el proceso penal es el sismógrafo de la Constitución Política del Estado. ${ }^{28}$ Precisamente, como consecuencia de la intensa actividad persecutoria desarrollada por el Ministerio Público en contra del imputado, los ordenamientos jurídicos compatibles con un Estado de Derecho han consagrado una serie de mecanismos que permiten -si bien no eliminar por completo cualquier afectación de garantías fundamentalesregular los requisitos que justifican la intervención estatal dirigida al esclarecimiento de conductas constitutivas de delitos.

Ya en el Mensaje enviado por el Ejecutivo al Parlamento al momento de ingresar el proyecto de Código Procesal Penal, se recalcaba la relevancia que el legislador le concede al resguardo de las garantías, señalando la importancia de:

Ocuparse de la reforma procesal penal para, a través de ella, fortalecer las garantías. (Ello) constituye (...) una tarea exigida por los principios en materia de derechos fundamentales. La reforma al proceso penal importará, por lo mismo, un mayor goce cotidiano de los derechos humanos.

En concreto, para la determinación específica de aquellos derechos susceptibles de ser afectados en el marco de un proceso penal, resulta relevante destacar la regulación contenida en el artículo 19 de la Constitución Política, así como aquella establecida en los artículos 14 del Pacto Internacional de Derechos Civiles y Políticos ${ }^{29}$ y $8^{\circ}$ de la Convención Americana de Derechos Humanos. ${ }^{30}$

A nivel legal, nuestro legislador ha consagrado un amplio catálogo de garantías de las que todo imputado goza, contenido -fundamentalmente- en los artículos 93 y 94 del CPP. Relevante resulta además, el reconocimiento de la calidad del imputado desde la primera actuación del procedimiento dirigido en su contra, de conformidad con lo dispuesto en el artículo $7^{\circ}$ inc. $1^{\circ} \mathrm{CPP}$, así como el denominado ámbito de defensa consagrado en el artículo $8^{\circ} \mathrm{CPP}$, que refuerza el derecho a asistencia letrada e intervención de dicho profesional en el procedimiento penal desde las primeras actuaciones del mismo.

En lo referido a la obtención de material probatorio, aspecto central de este trabajo, cobran especial relevancia aquellas garantías especialmente susceptibles de ser vulneradas por parte de los órganos persecutores durante el transcurso de una investigación criminal. Entre éstas destacan el derecho a la integridad física y psíquica (artículo 19 Nr. 1 CPR); el derecho a guardar silencio (artículo $8 \mathrm{~g}$ ) $\mathrm{CADH}$ ); a la inviolabilidad del hogar (artículo 19 Nr. 5 CPR); a la inviolabilidad de las comunicaciones (artículo 19 Nr. 5 CPR); y el derecho

\footnotetext{
28 Roxin (2006), p. 10.

${ }^{29}$ Firmado el 16 de diciembre de 1966 y ratificado el 10 de febrero de 1972.

30 Firmado el 22 de septiembre de 1969 y ratificado el 21 de agosto de 1990.
} 
a la defensa letrada (artículo 19 Nr. 3 inc. 2 CPR, artículo 14.3 d) PIDCP, artículo 8 d) CADH).

La eficacia del sistema de protección de garantías fundamentales establecido en nuestra legislación, comprende no solamente el reconocimiento de derechos a favor del imputado, sino que precisa además - para ser eficaz- de la consagración de mecanismos de control preventivos y represivos dirigidos a evitar y sancionar, respectivamente, el incumplimiento de las reglas de obtención de prueba por parte de las policías.

Los mecanismos preventivos de control, se erigen como exigencias legales concretas, establecidas para la obtención y posterior utilización de material probatorio dentro del marco de la legalidad. Sin el cumplimiento de estos requisitos, la prueba obtenida adolecerá de un vicio de origen. Consecuentemente, ante la constatación de una infracción a una regla de obtención de prueba, el ordenamiento contempla diversos remedios dirigidos a sancionar dicha vulneración. Dichos mecanismos represivos comprenden no sólo herramientas procesales, sino que alcanzan también al derecho penal, civil y administrativo sancionador, siendo sus destinatarios, generalmente, los policías infractores.

Un mecanismo esencial de resguardo de garantías, de carácter preventivo, lo constituye la cláusula de protección general de garantías aplicable al proceso de producción de prueba, consagrada en el artículo $9^{\circ}$ inc. $1^{\circ} \mathrm{CPP}$. Por medio de dicha regla se exige a los órganos persecutores contar con la debida autorización judicial previa como requisito insoslayable para efectuar cualquier actuación del procedimiento que afectare derechos reconocidos a favor del imputado. La práctica de múltiples diligencias de investigación, que sin contar con el consentimiento del afectado afectaren garantías, requerirán necesariamente dicha autorización como requisito necesario para llevarse a cabo.

Asimismo, en un sistema como el consagrado en el CPP, en el cual la obtención de prueba por parte del Ministerio Público con auxilio de las policías debe desarrollarse de conformidad a las reglas establecidas por el ordenamiento jurídico vigente, el legislador ha consagrado requisitos estrictos que regulan detalladamente los mecanismos mediante los cuales dicha prueba puede ser legalmente obtenida (fundamentalmente las reglas contenidas en el Título I del Libro II del CPP).

Por otro lado, a efectos de asegurar el respeto y vigencia de las garantías consagradas a favor del imputado ante su infracción, el legislador ha consagrado distintos mecanismos reactivos de control y sanción de una ilegalidad ya cometida, vinculados al proceso de producción probatoria. Entre estos cabe destacar:

a. La cautela de garantías, regulada en el artículo 10 CPP, destinada a restablecer el ejercicio de las garantías de las que goza el imputado, en caso de afectación o amenaza de afectación a las mismas.

b. La nulidad procesal, regulada en los arts. 159 y ss. del CPP.

c. La exclusión de prueba por ilicitud, posibilidad reconocida principalmente en el artículo 276 inc. $3^{\circ} \mathrm{CPP}$.

d. El recurso de nulidad, establecido en los arts. 372 y ss. CPP, especialmente las causales de procedencia del mismo consagradas en los arts. 373 a) y 374 b), c) y d) CPP. 
El marco normativo recién esbozado, nos demuestra la enorme relevancia que el legislador ha otorgado al respeto de las garantías fundamentales en el proceso penal. Dicha importancia se traduce - como veremos- en la consagración de un sistema transversal de resguardo de la licitud probatoria, que trasciende una oportunidad procesal específica.

\section{MEGANISMOS DE GONTROL DE LA LICITUD PROBATORIA GONSAGRADOS EN EL GPP}

A diferencia de su predecesor, el CPP consagró por vez primera en nuestro ordenamiento, una regla de exclusión de prueba en atención a su origen ilícito, a saber, el artículo 276 inc. $3^{\circ} \mathrm{CPP}$. Dicha norma, sabemos, desempeña su función directamente en la etapa intermedia o de preparación del juicio oral, generando la exclusión de aquellos elementos de prueba que hubieren sido obtenidos por los órganos persecutores con inobservancia de Garantías Fundamentales. El efecto de la aplicación de dicha regla, cuyo estudio pormenorizado excede el alcance de este trabajo, consiste en la depuración de la prueba de cargo, impidiendo que aquella ilícitamente obtenida sea incluida en el auto de apertura, y con ello, llegue a conocimiento del tribunal de fondo.

Consumado dicho efecto por resolución firme, podría argumentarse - en línea con la doctrina y jurisprudencia que rechaza la valoración negativa- que la labor del tribunal de juicio oral en lo referido al tratamiento de la ilicitud probatoria, se encuentra constreñida por la decisión previa del juez de garantía pronunciada en la audiencia preparatoria. De este modo, cualquier examen de ilicitud de prueba efectuado por el tribunal de fondo implicaría una soterrada revisión de lo resuelto previamente. Dicho argumento resulta equívoco.

En efecto, si bien en la regulación del Juicio Oral el legislador (lógicamente) no ha consagrado una regla equivalente al artículo 276 CPP, no ha privado del todo a dicho órgano jurisdiccional de la posibilidad de efectuar un examen de licitud de la prueba que ante él se rinda.

El examen de licitud de la prueba en la audiencia de juicio oral constituye una posibilidad real, contemplada por el legislador. Sin perjuicio de ello, esta posibilidad puede catalogarse de fragmentaria, reduciendo su procedencia a un par de hipótesis puntuales.

En primer lugar, el artículo 334 inc. $2^{\circ} \mathrm{CPP}$, regla que impide introducir al juicio oral documentos y registros propios de la investigación, pese a encontrarse en alguna de las hipótesis que autorizan excepcionalmente su incorporación (artículos 331 y 332 CPP), si dichos documentos o actas han sido obtenidos en vulneración de garantías fundamentales.

En segundo lugar, el artículo 336 CPP, que autoriza la recepción en juicio de la llamada "prueba no solicitada oportunamente", permite a los intervinientes controvertir la autenticidad, veracidad e integridad de la nueva prueba ofrecida, aspecto que resulta posible vincular a un examen de licitud probatoria en atención a su origen.

Dichas reglas demuestran la intención del legislador en orden a impedir ya no un contacto del Tribunal de Juicio Oral con prueba contaminada, asunto a esas alturas imposible, sino evitar que material probatorio ilícitamente obtenido pueda constituir el fundamento de una sentencia condenatoria. La posibilidad en estos casos de contaminación 
del tribunal de juicio oral es tolerada por el legislador, en pos del resguardo de un interés superior.

\section{LAS PROHIBIGIONES DE VALORAGIÓN DE PRUEBA GOMO MECANISMO RESIDUAL DE GONTROL DE GARANTÍAS EN MATERIA DE OBTENGIÓN PROBATORIA}

En lo que a este trabajo respecta, es la hipótesis de exclusión probatoria reconocida en la segunda parte del inciso tercero del artículo 276 CPP la que debemos contrastar a la luz de la regulación de la ilicitud probatoria establecida en distintas etapas procesales. En este sentido, resulta importante tener presente que la regla de exclusión probatoria no permite solucionar todas las dificultades vinculadas a la ilicitud probatoria suscitadas a lo largo del proceso penal, existiendo numerosos problemas frente a los cuales dicha regla no otorga solución. ${ }^{31}$

Así, nuestra legislación no establece - por ejemplo- como debe actuar un tribunal enfrentado a prueba ilícita en la audiencia de procedimiento abreviado, mecanismo que sabemos, no contempla una etapa de discusión sobre la ilicitud de la prueba que sustenta la acusación. Así, ¿debe entenderse la aceptación expresa de los antecedentes de la investigación que, de conformidad con el artículo 406 inciso $2^{\circ} \mathrm{CPP}$ sustentan dicho procedimiento, como una renuncia al derecho a impugnar la ilicitud de la prueba en la audiencia del artículo 411 CPP? ¿Resulta razonable privar al tribunal de fondo, de la posibilidad de no fundamentar una sentencia definitiva en base a prueba ilícitamente obtenida?

Similares preguntas se repiten en el procedimiento ordinario: ¿debe el juez de garantía, hacer caso omiso ante la presencia de prueba ilícita al momento de resolver, por ejemplo, una solicitud de imposición de una medida cautelar promovida tras la declaración de ilegalidad de la detención, aduciendo simplemente que "no es la oportunidad procesal para discutir tales asuntos"?

En lo relativo al juicio oral, el problema referido al tratamiento de aquellos elementos probatorios erróneamente incluidos en el auto de apertura, pese a adolecer de alguna de las causales de exclusión probatoria contempladas en el artículo 276 CPP, ${ }^{32}$ o de aquellas situaciones en las cuales la ilicitud probatoria quede de manifiesto por vez primera en la audiencia de juicio no se encuentra expresamente regulado por parte del legislador. A este respecto: ¿Debe el Tribunal de Juicio Oral hacer oídos sordos ante la presencia de prueba manifiestamente ilícita, alegando que dicha discusión resulta temporalmente improcedente?

Desde luego que no. Todo órgano jurisdiccional que deba fundar una resolución judicial en base a elementos probatorios se encuentra legitimado al resolver, para examinar el origen y, con ello, la legalidad de los antecedentes que la sustentan. De este modo, en caso de constatar el órgano adjudicador una infracción de garantías en lo referido a su obtención, deberá necesariamente abstenerse de valorar dicho medio de prueba. Para ello no es necesario recurrir expresamente a una regla de exclusión probatoria, sino que basta con

${ }^{31} \mathrm{Al}$ respecto, vid. CORREA (2018), pp. 155 y ss.

32 Vid. CERDA (2010), p. 148; HORVITZ y LÓPEZ (2004), p. 197. 
exigir a los tribunales someter su actuación al respeto de los derechos y garantías reconocidas por nuestro ordenamiento jurídico.

En efecto, como ilustra la experiencia comparada que se analizará a continuación, la inexistencia de disposiciones legales que reglamenten el tratamiento de la prueba ilícita en general o en alguna oportunidad procesal concreta, no ha impedido el reconocimiento de dicha teoría en otros ordenamientos. En estos casos, la necesidad de dotar al tribunal de un remedio eficaz que le permita controlar la licitud de los medios de prueba que sustentarán una sentencia se impone - generalmente por vía jurisprudencial- frente a la indiferencia del legislador.

A este respecto, y ante la ausencia de regulación general sobre el tema en la Ordenanza Procesal Penal de 1877, desde comienzos del siglo pasado ${ }^{33}$ la doctrina y posteriormente la jurisprudencia alemana ha solucionado el problema referido al origen ilícito de los elementos de prueba recabados por la policía, por medio del reconocimiento de las llamadas prohibiciones probatorias, la más relevante de las cuales corresponde a las prohibiciones de valoración de prueba, cuyo efecto radica en impedir que medios probatorios ilícitamente obtenidos sean considerados como elementos de convicción por el juez en la sentencia definitiva. ${ }^{34}$

A efectos de conceder una protección integral a las Garantías Fundamentales a lo largo del proceso penal, la doctrina mayoritaria ${ }^{35}$ como la jurisprudencia del Tribunal Constitucional Federal, ${ }^{36}$ han sostenido que las prohibiciones probatorias pueden ser declaradas por el tribunal en cualquier etapa del procedimiento penal.

Por último, es deber del tribunal, al reconocer una prohibición de valoración en un caso específico, explicitar en su resolución los fundamentos por las cuales llega a tal conclusión, misma obligación que recae en el tribunal con competencia en lo penal en el sistema chileno, al decidir valorar negativamente algún medio de prueba.

\section{PROHIBIGIONES DE VALORAGIÓN DE PRUEBA EN LA AUDIENGIA DE JUIGIO ORAL: LA LLAMADA VALORAGIÓN NEGATIVA DE LA PRUEBA}

Como he sostenido previamente, ${ }^{37}$ siguiendo una línea argumentativa previamente definida por Hernández, ${ }^{38}$ el Tribunal de Juicio Oral no debe valorar aquellos elementos de

\footnotetext{
${ }^{33}$ BELING (1903), passim.

34 Vid. Correa (2018), pp. 146 y ss.; LÖWE-Rosenberg (2016), Introducción Sección L. Rdn. 7; JAHN (2008a), pp. C 1 - C 128, p. C 31; Pitsch (2009), p. 78; Rogall (1999), p. 126; WOHLERS (2016), p. 434.

35 Dallmeyer (2008), pp. 78 y s.; DenCKer (1994), p. 670; DenCKer (1977), pp. 53 y 75; EISENBerg (2015), números marginales 334, 356 y 635; HengSTENBERG (2007), pp. 30 y s.; MAUl y EscheLbaCH (1996), p. 69; Pitsch (2009), p. 83; Rogall (2011), p. 536; Rogall (1999), p. 130; Rogall (1979), pp. 7 y s.; SCHLOTHAUER (2002), pp. 761 y ss.; STÖRMER (1994), p. 625; STÖRMER (1992), pp. 241 y 394.

36 Ver a este respecto: BVerfGE 44, 353 (383, s.); 34, 238 (238, ss.); OLG Frankfurt, NStZ 1988, 425; JAHN (2008b), p. 282.

37 CORREA (2018), p. 164.

${ }^{38}$ En un sentido similar, DONOSO (2008), pp. 39 y ss.; HERNÁNDEZ (2002), p. 60, nota al pie No 3; HernáNDEZ (2002), pp. 89 y ss.
} 
prueba vinculados a una infracción de Garantías Fundamentales, con independencia de lo resuelto previamente en la etapa intermedia.

En caso de privar al tribunal de la posibilidad de efectuar dicho examen de licitud probatoria, se obligaría al juez a fallar conscientemente basado en una vulneración de garantías, asunto inaceptable en cualquier ordenamiento que pretenda resguardar efectivamente las garantías. ${ }^{39}$ En efecto, permitir toda valoración de un determinado elemento probatorio en la etapa de juicio, independientemente de la licitud de su origen o producción, bajo el pretexto formalista de no encontrarse facultado el tribunal de fondo para examinar la licitud de prueba ya incorporada, daría lugar a una incoherencia interna del sistema, generando una desprotección de garantías en la etapa de juicio oral.

Lo anteriormente señalado queda reafirmado por la jurisprudencia de la Corte Suprema, tribunal que en causa Rol No 23.683-2014, sostuvo (Considerando $9^{\circ}$ ) que: ${ }^{40}$

(...) cuando el Juez del fondo valora en el juicio y en la sentencia que se pronunció los referidos antecedentes revestidos de ilegalidad, se incurrió en la materialización de la infracción a las Garantías constitucionales del imputado que aseguran su derecho a un debido proceso y a que la sentencia que se pronuncie por el tribunal sea el resultado de una investigación y un procedimiento racionales y justos, por cuanto dicha exigencia supone que cada autoridad actúe dentro de los límites de sus propias atribuciones (...).

La estructura misma del sistema de ilicitud probatoria del CPP impide entender que -salvo las excepciones mencionadas- el Tribunal de Juicio Oral se encuentra facultado para excluir aquella prueba erróneamente admitida en la audiencia de preparación. ${ }^{41}$

A pesar de ello, exclusión y valoración de prueba, son dos conceptos distinguibles en cuanto a sus efectos y consecuencias. La preclusión referida a la exclusión de prueba que afecta al Tribunal de Juicio Oral no prejuzga la posibilidad de impedir la valoración de ciertas pruebas en la sentencia definitiva. Este aspecto, entendemos, se encuentra comprendido dentro de las prerrogativas propias del tribunal de fondo al valorar la prueba en la sentencia definitiva.

$\mathrm{Al}$ respecto, cabe tener presente que la existencia de prohibiciones de prueba no resulta del todo ajena a nuestra legislación procesal, reconociéndose expresamente su procedencia en el caso regulado en el artículo 220 inciso final CPP. Dicha disposición contempla un catálogo de objetos y documentos no susceptibles de ser incautados en el marco de una investigación penal. El inciso final de dicha regla establece las consecuencias derivadas de una infracción a la referida prohibición, señalando que "[s]i en cualquier momento del procedimiento se constatare que los objetos y documentos incautados se encuentran entre

\footnotetext{
39 Hernández (2002), p. 90.

40 Ministerio Público con S.E.A.R. (2014).

${ }^{41}$ Como ha sostenido reiteradamente la Corte Suprema, la prueba erróneamente aceptada en la audiencia de preparación del Juicio Oral no puede ser excluida, ni de oficio, ni a solicitud de partes por el Tribunal de Juicio Oral. Vid. Ministerio Público con E.F.S. y otro (2003); M.A.G.M. con A.E.B.O. (2005); Chuica Lebien y Santana Barra (2004); Ministerio Público con R.A.V.I. (2005); Ministerio Público con F.A.R.S. (2008); Ministerio Público con M.G.B. (2011). En la literatura vid. DONOSO (2008), p. 39.
} 
aquellos comprendidos en este artículo, ellos no podrán ser valorados como medios de prueba en la etapa procesal correspondiente".

Como queda de manifiesto, el CPP ha reconocido en esta hipótesis una sanción procesal distinta de la exclusión para los casos en los cuales se produzca una obtención probatoria contraria a lo allí dispuesto. En efecto, de haber querido el legislador asimilar la situación en la que se encuentran objetos y documentos erróneamente incautados con la exclusión de prueba, hubiera hecho directa referencia a la oportunidad procesal en que dicha posibilidad es discutida, tal como a modo de referencia lo establece el artículo 132 inciso final CPP, que desvincula expresamente la declaración de ilegalidad de la detención con el efecto de cosa juzgada, en relación con las solicitudes de exclusión de prueba que se hagan oportunamente, de conformidad a lo previsto en el artículo 276 CPP.

Tal como sucede en el caso recién descrito, la respuesta a los problemas de ilicitud probatoria generados fuera de la audiencia de preparación puede ser resuelta por medio del reconocimiento de prohibiciones de valoración probatorias, figura equivalente a la valoración negativa de la prueba.

\section{FUNDAMENTO LEGAL DE LA EXISTENGIA DE PROHIBICIONES PROBATORIAS EN EL DEREGHO GHILENO}

De acuerdo a la tesis aquí defendida, todo tribunal que deba fundar una resolución judicial en base a la valoración de elementos probatorios se encuentra legitimado para examinar su licitud. De este modo, en caso de constatar el órgano adjudicador una ilegalidad en lo referido a su obtención o producción deberá necesariamente abstenerse de valorar dicho medio de prueba, aun sin contar con una norma expresa que así lo disponga. Para llegar a dicha conclusión, existen diversos fundamentos.

A nivel supralegal, la prohibición de valoración se sustenta en la obligación que asiste a todo órgano del Estado (establecida en el artículo $6^{\circ}$ inc. $1^{\circ}$, en relación con el artículo $5^{\circ}$ inc. $2^{\circ}$ de la Constitución Política) de someter su actuar al resguardo de los Derechos Fundamentales establecidos en la Constitución y los Tratados Internacionales importa un imperativo para el juez, exigible ante la presencia de una infracción de garantías constatada a lo largo del procedimiento.

De este modo, permitir la valoración de un determinado elemento probatorio en el juicio oral, argumentando que el vicio del que éste adolece podría ser posteriormente remediado por los tribunales superiores conociendo de un recurso de nulidad, generaría una incoherencia interna del sistema: vulneraría el respeto que el legislador ha conferido a las citadas garantías a lo largo de todo el proceso penal, obligando al tribunal a fallar a sabiendas utilizando prueba ilícita, con el consiguiente gasto de recursos que implicará repetir el juicio.

Como previamente se esbozó, el fundamento legal que permite en nuestro sistema reconocer prohibiciones de valoración (v.gr., de valorar negativamente) sobre los elementos de prueba incorporados al juicio reconducibles a una infracción de garantías, se encuentra en el artículo 297 CPP, disposición que obliga al tribunal al momento de valorar la prueba, a hacerse cargo de toda la prueba producida. Dicha obligación comprende expresamente a 
la prueba desestimada, independiente de los motivos para ello, comprendiendo así paradigmáticamente, aquella prueba valorada negativamente o aquella cuyos resultados resulten poco fiables. En todos estos casos, deberá el tribunal indicar las razones tomadas en cuenta para ello. Sólo por medio de dicha fundamentación se dará cumplimiento a la exigencia que a este respecto exige el artículo 342 letra c) del CPP.

\section{IX. ¿REITERAGIÓN DE UNA DISGUSIÓN ZANJADA? NO NEGESARIAMENTE}

Se ha argumentado por parte de los detractores de la posición aquí defendida, que la discusión en el juicio oral sobre el origen de la prueba importaría revivir una discusión ya resuelta, promovida en una etapa anterior del procedimiento. Dicha observación, si bien no ataca el fundamento último del reconocimiento de prohibiciones de valoración en el juicio oral, debe ser contextualizada.

$\mathrm{Al}$ respecto, cabe mencionar que en muchos casos el origen ilícito de un determinado medio de prueba será desconocido por los intervinientes y el tribunal en la audiencia preparatoria, pues la discusión sobre exclusión allí promovida se encuentra limitada a los antecedentes con los que se cuentan en dicha oportunidad, reconducibles a ciertas piezas de la carpeta de investigación. La posibilidad de presentar prueba para acreditar la ilicitud constituye una instancia no reconocida (hasta ahora) por nuestro legislador. Así, cabe suponer que en algunas oportunidades será en la audiencia de juicio donde, paradigmáticamente, tras el examen y contraexamen practicado a testigos, imputado y peritos, tome conocimiento el tribunal de circunstancias antes ignoradas y que pudiesen dar a conocer una ilicitud de origen, hasta entonces ignorada. La discusión sobre el origen de un medio de prueba contará en este caso con elementos previamente ignorados y no expuestos en la audiencia de preparación, salvando así las objeciones planteadas.

En este sentido, la Corte de Apelaciones de Valparaíso, sostuvo en la ya citada sentencia rol No 1.920-2017, Ministerio Público con B.C.E. (2017), que:

sostener una posición contraria (supresión de cualquier examen de licitud probatoria en el juicio oral) implicaría que si en el transcurso del juicio oral surgiese la evidencia que una prueba ha sido obtenida con vulneración de garantías constitucionales, lo que no pudo ser detectado en la audiencia ante el juez de garantía, ella no pudiese ser objeto del control por parte de los jueces de la instancia en cuanto a su ilicitud y su ineficacia en la valoración (...).

Ahora bien, lo que efectivamente debiese estar vedado para el Tribunal de Juicio Oral es la posibilidad de reconocer una prohibición probatoria a partir de los mismos antecedentes previamente expuestos en la audiencia de preparación, y desestimados como sustento de una exclusión probatoria. Dicha situación, efectivamente, se asimila a un recurso encubierto en contra del auto de apertura, escenario inaceptable dentro del ámbito de aplicación de la tesis aquí defendida. 
Así, la interpretación aquí propuesta, busca limitar el examen de licitud probatoria al mérito de la prueba rendida, evitando así una reiteración de una discusión pasada. Lo anterior, recalcamos, no exime al tribunal de la posibilidad de constatar y consecuentemente sancionar, una ilicitud probatoria.

\section{VALORAGIÓN NEGATIVA Y EXGLUSIÓN DE PRUEBA: ¿UN FRAUDE DE ETIQUETAS?}

Como previamente se expuso, el principal argumento utilizado en contra de la valoración negativa de la prueba sostiene que este mecanismo sería, en realidad, una exclusión probatoria disfrazada. En otras palabras, se trataría de un fraude de etiquetas dirigido a alterar la decisión adoptada por el juez de garantía en la audiencia de preparación del juicio oral. Dicho argumento es incorrecto.

$\mathrm{Al}$ respecto, cabe tener presente que nuestro sistema diferencia claramente exclusión de valoración, como dos mecanismos procesales distintos, cuyos efectos y consecuencias, si bien comparten elementos en común, no pueden ser automáticamente equiparados.

En primer término, la exclusión probatoria constituye una herramienta de supresión de elementos de prueba, cuyos efectos inciden directamente en la audiencia de juicio oral, oportunidad en la cual la prueba ya excluida por resolución firme no puede ser presentada en el juicio. El Tribunal de Juicio Oral no tendrá contacto alguno con la prueba previamente excluida.

La consecuencia jurídica que acarrea el acoger alguna de las hipótesis reguladas en el art. 276 del CPP es -en todos los casos- la misma: exclusión de dichos elementos de prueba del auto de apertura del juicio oral (art. 277 e) CPP), impidiéndose la incorporación de dicha prueba a la audiencia de juicio oral. De este modo, como lo ha reconocido la jurisprudencia, ${ }^{42}$ el art. 276 CPP actúa como una regla de admisibilidad probatoria, cuya función consiste en regular la inclusión de prueba en etapas posteriores del procedimiento. Nada nos dice dicha regla respecto de la valoración de la prueba admitida, ni mucho menos del tratamiento que debe darse a la prueba no controlada en la audiencia preparatoria, aspecto sobre el cual como ya se mencionó- el tribunal de fondo posee facultades expresamente concedidas de control de la licitud probatoria.

La diferencia antes mencionada queda de manifiesto precisamente en uno de los argumentos entregados por Aristegui para oponerse al reconocimiento de una valoración negativa: la contaminación del tribunal que genera el reconocimiento de una prohibición de valoración, efecto que no es posible atribuir a la exclusión probatoria. De este modo, queda en evidencia que, si bien se trata de dos mecanismos destinados a resguardar el respeto de las garantías fundamentales, sus consecuencias y efectos no resultan equiparables.

Por último, cabe recordar que un ordenamiento procesal suele consagrar distintas herramientas para alcanzar un mismo objetivo. Así, por ejemplo, en el proceso civil una infracción a la cosa juzgada puede alegarse por diferentes vías (paradigmáticamente por

${ }^{42}$ Ministerio Público con C.R.G. (2010) (Cons. 14º). 
medio de una excepción, del recurso de casación en la forma, en incluso en ciertos casos, por medio de la acción de revisión). Dichos mecanismos no se contraponen ni resultan excluyentes entre sí, sino que se complementan con la finalidad de resguardar un valor considerado esencial por el legislador, a pesar que las consecuencias de acoger uno u otro mecanismo pudiesen diferir. En el proceso penal, los defensores de la supuesta incompatibilidad de vías para alegar la ilicitud probatoria, debiesen consecuentemente criticar la existencia de la causal de nulidad del artículo 373 letra a) CPP como mecanismo de revisión de inclusiones probatorias erradas en sede de preparación al juicio oral, ya discutidas y firmes, en tanto la discusión sobre la causal de nulidad invocada se correspondería, en gran medida, con una cuestión ya zanjada.

Concordante con dicha postura, en un fallo recientemente pronunciado ( $R o l N^{\circ} 375-$ 2019), sostuvo la Corte de Apelaciones de Valparaíso (Considerando $7^{\circ}$ ) que: ${ }^{43}$

El artículo 276 del Código Procesal Penal impide que los jueces puedan valorar positivamente una prueba lograda con vulneración de las Garantías constitucionales de los imputados. La circunstancia que ya haya existido previamente un pronunciamiento sobre el particular por parte del juez de garantía, no es óbice para decidir la valoración negativa de la prueba ilícita. Más aún, el Tribunal Oral en lo Penal debe prescindir de esta prueba, pues lo contrario llevaría a concluir que dicho tribunal debe fallar en la conciencia y conocimiento de la vulneración de Garantías constitucionales y procesales de los imputados.

Del mismo modo, la Corte de Apelaciones de Valparaíso se pronunció en la sentencia Rol No 1920-2017, Ministerio Público con B.C.E. (2017), en el sentido aquí expuesto:

Que, de esta manera, la decisión de los jueces a quo, en cuanto a negarle valor probatorio a la prueba, tanto en cuanto a la declaración de los funcionarios policiales como a los hallazgos no implica desconocer o revisar lo resuelto por el Juzgado de Garantía y que está contenido en el auto de apertura, sino que se encuentra vinculado con la valoración y valor probatorio de los mismos, en relación a la decisión de la controversia, lo que por cierto es facultad exclusiva, establecida por Ley, de los Jueces del Tribunal del Juicio Oral, con la libertad y los límites contenidos en el artículo 297 del Código del ramo.

\section{LA SUPUESTA GOMPENSAGIÓN PROBATORIA GOMO ARGUMENTO EN GONTRA DE LA VALORAGIÓN NEGATIVA}

Se ha sostenido que el reconocimiento de prohibiciones probatorias llevaría a que el Tribunal de Juicio Oral, al verse obligado a desestimar prueba de cargo relevante, intente distribuir el valor probatorio de ésta en los elementos incriminatorios restantes. Con ello, prosigue el argumento, la sentencia condenatoria se tornaría inexpugnable, al no tener la Corte en sede de nulidad facultades para examinar la valoración de la prueba efectuada por el tribunal de fondo.

${ }^{43}$ Ministerio Público con M.J.B. y otros (2019). 
Si bien dicho argumento es interesante, no resulta convincente. Lo primero que al respecto cabe señalar, es que la supuesta redistribución probatoria constituye una mera especulación, carente de sustento empírico. En efecto, no existe motivo alguno para desprender dicha consecuencia de la valoración negativa de ciertos elementos probatorios. Por el contrario, lo lógico y esperable, en caso que el Tribunal de Juicio Oral que decida efectivamente valorar negativamente cierta prueba, consecuentemente funde su convicción exclusivamente en los medios de prueba restantes. Desde luego, la valoración negativa de uno o más medios de prueba no afectará a la prueba no contaminada, siendo ésta a priori susceptible de fundar una decisión condenatoria. ${ }^{44}$

En segundo lugar, el argumento parte de la asunción de una interpretación subjetivista del estándar de prueba penal, cuya validez resulta -a lo menos-cuestionable. Al respecto, Accatino ${ }^{45}$ ha sostenido correctamente que la interpretación tradicional, que descarta controlar por vía del recurso de nulidad la suficiencia o insuficiencia de los elementos de juicio para tener por probado un cierto enunciado empírico de acuerdo al estándar de prueba, merece ser revisada.

En efecto, el pretendido rechazo a una revisión por parte del tribunal de nulidad acerca de la acreditación de los hechos, constituye un lugar común que debe ser relativizado. Por lo anterior, como ha sostenido otro autor, ${ }^{46}$ la separación lógica entre las comprobaciones fácticas y la valoración jurídica constituye una distinción imposible de defender como criterio delimitador de la nulidad: cuando una norma jurídica es aplicada a un hecho insuficientemente acreditado estaríamos, en realidad, frente a una incorrecta aplicación de la ley.

En este sentido, la causal de nulidad establecida en el 374 letra e) se erige como la posibilidad de impugnación de las conclusiones probatorias, en caso que sean insuficientes o defectuosas a la luz de las condiciones prescritas por el artículo 297 del CPP.

\section{GONSEGUENGIAS INDESEADAS: LA GONTAMINAGIÓN DEL TRIBUNAL DE JUICIO ORAL}

La decisión sobre el modelo a adoptar para el tratamiento de la prueba ilícita corresponde en primer término al legislador, y a falta de decisión al respecto, a la jurisprudencia. Así, los dos modelos que se han mencionado en el presente artículo representan mecanismos diferenciados y complementarios de sanción de la ilicitud probatoria, cuyo elemento en común radica -en último término- en el hecho de impedir que un tribunal penal sustente una sentencia condenatoria en medios de prueba ilícitamente obtenidos.

\footnotetext{
${ }^{44}$ En este sentido, resulta interesante destacar la sentencia Ministerio Público con S.M.B. (2012), Rol No 597-2017 de la Corte de Apelaciones de Concepción, en la cual el tribunal, frente a un recurso de nulidad interpuesto por la causal del art. 374 letra e) CPP, analiza la capacidad de la prueba rendida en juicio para tener por acreditados los hechos, y finalmente, alcanzar el estándar de prueba necesario para condenar.

45 ACCatino (2009), p. 355.

${ }^{46}$ CORTEZ (2006), pp. 136 y ss.
} 
En este sentido, las ventajas del modelo de exclusión probatoria -herramienta primaria de sanción de casos de ilicitud probatoria en nuestro sistema procesal penal-, sobre el modelo de prohibiciones probatorias, radica principalmente en sus efectos. La exclusión probatoria genera la ausencia de cualquier contacto por parte del tribunal de fondo con la prueba contaminada de ilicitud, impidiendo con ello que ésta sea - consciente o inconscientemente- ${ }^{-}$considerada en la resolución del asunto. ${ }^{47}$

Por el contrario, en aquellos casos en los cuales el examen de ilicitud de la prueba es efectuado por el mismo tribunal encargado de adoptar una decisión en base a la prueba cuestionada (como sucede en Alemania, y parcialmente en Chile, de acuerdo a lo ya expuesto), es inevitable un contacto del tribunal con la prueba contaminada. ${ }^{48} \mathrm{Al}$ respecto, podría intuirse - como se ha expuesto- que frente a dicha disyuntiva, un tribunal podría intentar compensar la prueba que no resulta posible valorar con los elementos restantes a efectos de llegar a la misma conclusión condenatoria. Dicha afirmación peca de exceso. Las consecuencias que la contaminación del tribunal genera son inciertas, y no han sido - hasta ahora-debidamente estudiadas, no siendo posible darlas por sentado.

Con todo, los beneficios que proporciona un sistema en el cual todo tribunal penal encargado de emitir un pronunciamiento pueda impedir que la prueba ilícita pueda sustentar una resolución judicial, superan a los inconvenientes que éste pudiese generar.

\section{GONGLUSIONES}

Lo expuesto en este trabajo permite concluir que nuestro legislador no ha consagrado un solo mecanismo para dar tratamiento a los diversos problemas asociados al tratamiento de aquellos medios de prueba ilícitamente obtenidos. Por el contrario, si bien nuestro CPP consagra una regla de exclusión de prueba por ilicitud, dicha disposición debe ser debidamente complementada para dar adecuado tratamiento a problemáticas referidas al tratamiento de la prueba ilícita fuera de la etapa intermedia.

El respeto por las garantías fundamentales, en tanto fundamento y criterio material de justificación de la exclusión de prueba en nuestro sistema, constituye a su vez el sustento material que permite reconocer prohibiciones de valoración de prueba en el juicio oral. Dicha solución permite generar un sistema coherente de tratamiento de la ilicitud probatoria en distintas etapas del procedimiento penal, impidiendo que la sentencia condenatoria se sustente en material ilícitamente obtenido, y con ello, evitando una nueva infracción de aquellas garantías de las cuales todo imputado es titular.

\footnotetext{
47 Desde luego, en los casos de alta connotación pública podría resultar complejo que el sentenciador no tenga contacto alguno con la prueba ilícita, pues su contenido podría previamente haberse difundido por medio de la prensa.

48 Así, en el derecho alemán lo ha hecho notar WOHLERs (2016), p. 433.
} 


\section{BIBLIOGRAFÍA GITADA}

ACGATINO, Daniela (2009). "Forma y sustancia en el razonamiento probatorio. el alcance del control sobre la valoración de la prueba a través del recurso de nulidad penal", Revista de derecho de la Pontificia Universidad Católica de Valparaíso, Vol. 32, pp. 347-362.

Aristegui, Juan Pablo (2020). "La prueba ilícita ante la bifurcación del tribunal penal", Quaestio facti. Revista Internacional sobre Razonamiento Probatorio, No 1, pp. 177-198.

BeLing, Ernst (1903). Die Beweisverbote als Grenzen der Wahrheitserforschung im Strafprozess: Sonderausgabe (Wiss. Buchges).

CERDA, Rodrigo (2010). "La prueba ilícita y la regla de exclusión", Revista de la justicia penal, $\mathrm{N}^{\mathrm{o}}$ 6, pp. 99-176.

CorreA, Carlos (2018). "Más allá de la regla de exclusión: prohibiciones probatorias en el Derecho chileno - con especial referencia al Derecho alemán-", Politica Criminal, Vol. 13, No 25, pp. 144-174.

CORTÉS-MONROY, Jorge (2018). 'La ‘valoración negativa' como exclusión de la prueba ilícita en el juicio oral", Revista Ius et Praxis, Vol. 24, N 1, pp. 661-692.

Cortez, Gonzalo (2006). El recurso de Nulidad. Doctrina y juriprudencia (Lexis Nexis).

DALlmeyer, Jens (2008). Beweisfiuhrung im Strengbeweisverfahren (Books on Demand, 2a ed.).

Dencker, Friedrich (1994). "Über Heimlichkeit, Offenheit und Täuschung bei der Beweisgewinnung im Strafverfahren - Anmerkungen aus Anlaß zweier Entscheidungen des BGH", StV, pp. 667-683.

DencKer, Friedrich (1977). Verwertungsverbote im Strafprozeß: ein Beitrag zur Lehre von den Beweisverboten (Heymann).

DonOso, Samuel (2008). "Prueba ilícita, oportunidad para debatir y resolver sobre la regla de exclusión", Revista Derecho Mayor, No 7, pp. 35-42.

ECHEVERRÍA, Isabel (2010). Los derechos fundamentales y la prueba ilícita (Ediciones Jurídicas de Santiago).

EISENBERG, Ulrich (2015). Beweisrecht der StPO: Spezialkommentar (Beck, $9^{\mathrm{a}}$ ed.).

Hengstenberg, Achim (2007). Die Frühwirkung der Verwertungsverbote: eine Untersuchung der Bedeutung der Beweisverwertungsverbote für die strafprozessualen Verdachtsbeurteilungen (Kovač).

HERnÁNDEZ, Héctor (2002). "La exclusión de la prueba ilícita en el nuevo proceso penal chileno", Colección de Investigaciones furídicas, № 2.

HeRnÁnDEZ, Héctor (2008). "Prueba ilícita y recurso de nulidad: (o ¿Para qué está la Corte Suprema?)", Gaceta Furídica, No 332, pp. 60-68.

Horvitz, María Inés y LóPEz, Julián (2004). Derecho procesal penal chileno. T. II (Editorial Jurídica de Chile).

JAHN, Matthias (2008a). Beweiserhebungs- und Beweisverwertungsverbote im Spannungsfeld zwischen den Garantien des Rechtsstaates und der effektiven Bekämpfung von Kriminalität und Terrorismus. Band I 
Gutachten, Teil C, para el 67. Deutschen Furistentag 2008 (Ständigen Deputation des deutschen Juristentages).

JAHN, Matthias (2008b). "Grundfragen und aktuelle Probleme der Beweisverwertung im Straf- und Steuerstrafverfahren”, en JAHn, Matthias; KudLICH, Hans; STREnG, Franz (eds.), Strafrechtspraxis und Reform - Festschrift für Heinz Stöckel zum 70. Geburtstag (Duncker \& Humblot), pp. 259-286.

LA TERCERA (2019): "Vuelco en caso armas en San Antonio: anulan juicio que absolvió a imputados", RIVERA, Víctor, 19 de agosto de 2019, en: https://www.latercera.com/nacional/noticia/vuelco-caso-armas-san-antonioanulan-juicio-absolvio-imputados/771607/

LÖWE-RosenBerg (2016). Die Strafprozeßordnung und das Gerichtsverfassungsgesetz. Großkommentar, Band I: Einleitung (de Gruyter, 27a ed.).

Maul, Heinrich y EschelbaCH, Ralf (1996). “'Zur Widerspruchslösung' von Beweisverbotsproblemen in der Rechtsprechung", StraFo, pp. 66-70.

PITSCH, Christoph (2009). Strafprozessuale Beweisverbote: eine systematische, praxisnahe und rechtsvergleichende Untersuchung unter besonderer Berücksichtigung des Steuerstrafverfahrens, der Zufallsfunde und der Fernwirkungsproblematik (Kovač).

RogalL, Klaus (1979). "Gegenwärtiger Stand und Entwicklungstendenzen der Lehre von den strafprozessualen Beweisverboten”, ZStW, t. 91, pp. 1-44.

RoGALL, Klaus (1999). "Grundsatzfragen der Beweisverbote”, en HöPFEL, Frank y HÖPFEL, Huber (eds.), Beweisverbote in Ländern der EU und vergleichbaren Rechtsordnungen, Exclusion of Evidence Within the EU and Beyond, Europäisches Kolloquium Wien, 18. - 20. September 1997 (Iuscrim), pp. 119-148.

RoGALL, Klaus (2011). "Grund und Grenzen der 'qualifizierten' Belehrung im Strafprozess", en Geisler, Claudius; KrAAtz, Erik; Kretsahmer, Joachim; SaHnEIDER, Hartmut; SOWADA, Christoph (eds.), Festschrift für Klaus Geppert zum 70. Geburtstag (De Gruyter), pp. 519-547.

Roxin, Claus (2006). Derecho Procesal Penal (B de F, 25ª ed.).

SchlothauER, Reinhold (2002). "Zur Bedeutung der Beweisverwertungsverbote im Ermittlungs- und Zwischenverfahren", en PRITTwITZ, Cornelius; BAurmann, Michael; KuHlen, Lothar; MERKEL, Reinhard; NeSTLER, Cornelius; SCHulz, Lorenz (eds.), Festschrift für Klaus Lüderssen zum 70. Geburtstag (Nomos), pp. 761-772.

STÖRMER, Rainer (1992). Dogmatische Grundlagen der Verwertungsverbote: eine Untersuchung über die Strukturen strafprozessualer Verwertungsverbote unter dem Einfluss der Verfassung und der Grundsätze des öffentlichen Rechts (Elwert).

STÖRMER, Rainer (1994). "Strafprozessuale Verwertungsverbote in verschiedenen Konstellationen", $\mathcal{F} U R A$, pp. 621-628.

WOHLERs, Wolfgang (2016). "Verwertungs-, Verwendungs- und/oder Belastungsverbote die Rechtsfolgenseite der Lehre von den Beweisverwertungsverboten”, en HERZOG, 
Felix, Schlothauer, Reinhold; WOHLERS, Wolfgang (eds.), Rechtsstaatlicher Strafprozess und Bürgerrechte: Gedächtnisschrift für Edda Weßlau (Duncker \& Humblot), pp. 427-444.

\section{JURISPRUDENGIA GITADA}

\section{Alemania:}

BVerfGE 44, 353.

BVerfGE 34, 238.

OLG Frankfurt, NStZ 1988, 425.

\section{Chile:}

Canales Espinoza contra Tribunal Oral en lo Penal de Iquique (2018). Corte Suprema, 13 de marzo de 2018, Rol No 41.887-2017.

Chuica Lebien y Santana Barra (2004). Corte Suprema, 21 de abril de 2004, Rol No 5.869-2004. M.A.G.M. con A.E.B.O. (2005). Corte Suprema, 13 de enero de 2005, Rol No 5.154-2004.

Ministerio Público con B.C.E. (2017). Corte de Apelaciones de Valparaíso, 14 de noviembre de 2017, Rol No 1.920-2017.

Ministerio Público con C.R.G. (2010). Corte Suprema, 31 de mayo de 2010, Rol No 1618-2010. Ministerio Público con D.V.C. (2017). Corte Suprema, 17 de abril de 2017, Rol No 6.783-2017.

Ministerio Público con E.E.B (2017). Corte de Apelaciones de Santiago, 9 de marzo de 2017, Rol No 464-2017.

Ministerio Público con E.F.S. y otro (2003). Corte Suprema, 5 de junio de 2003, Rol No 1.4962003.

Ministerio Público con E.V.O. (2015). Corte Suprema, 24 de septiembre de 2015, Rol No 10.7722015.

Ministerio Público con F.A.R.S. (2008). Corte Suprema, 28 de julio de 2008, Rol No 2.521-2008.

Ministerio Público con I.M.R. (2013). Corte de Apelaciones de La Serena, 20 de enero de 2013, Rol No 319-2012.

Ministerio Público con 7.A.R. y otra (2017). Corte de Apelaciones de Santiago, 29 de noviembre de 2017, Rol No 3.103-2017.

Ministerio Público con M.G.B. (2011). Corte Suprema, 29 de junio de 2011, Rol No 3.016-2011.

Ministerio Público con M.J.B. y otros (2019). Corte de Apelaciones de Valparaíso, 3 de abril de 2019, Rol No 375-2019.

Ministerio Público con M.O.M. (2019). Corte de Apelaciones de Valparaíso, 6 de agosto de 2019, Rol No 1.337-2019.

Ministerio Público con P.R.C.E(2006). Corte Suprema, 20 de septiembre de 2006, Rol No 3.5702006.

Ministerio Público con R.A.C.P. (2016). Corte de Apelaciones de Concepción, 5 de diciembre de 2016, Rol No 909-2016. 
Ministerio Público con R.A.V.I. (2005). Corte Suprema, 14 de septiembre de 2005, Rol No 3.6662005.

Ministerio Público con R.H.A.G. (2019). Corte de Apelaciones de San Miguel, 26 de agosto de 2019, Rol No $1.857-2019$.

Ministerio Público con S.E.A.R. (2014). Corte Suprema, 22 de octubre de 2014, Rol No 23.6832014.

Ministerio Público con S.M.B. (2012). Corte de Apelaciones de Concepción, 4 de agosto de 2017, Rol No 597-2017. 